\title{
Decisional balance and self-efficacy of physical activity among the elderly in Rasht in 2013 based on the transtheoretical model
}

\author{
Seddigheh Abbaspour ${ }^{1}$, Rabiollah Farmanbar ${ }^{2}$, Fateme Njafi ${ }^{3}$, Arezoo Mohamadkhani Ghiasvand ${ }^{4}$, Leila \\ Dehghankar
}

${ }^{1}$ M.Sc. in Nursing Education, Lecturer, Department of Nursing \& Midwifery, Torbat Heydariyeh University of Medical Sciences, Torbat Heydariyeh, Iran

${ }^{2}$ Ph.D. in Health Education, Associate Professor, Department of Health Education and Health Promotion, Health and Environment Research Center, Social Determinants of Health Research Center (SDHRC), Health school, Guilan University of Medical Sciences, Rasht, Iran

${ }^{3}$ M.Sc. in Nursing Medical and Surgical, Department of Nursing \& Midwifery, Qazvin University of Medical Sciences, Qazvin, Iran

${ }^{4}$ M.Sc. in Nursing Management, School of Nursing \&Midwifery, Shahid Beheshti University of Medical Sciences, Tehran, Iran

${ }^{5}$ M.Sc. in Nursing Education, Lecturer, Department of Community Health Nursing, Faculty of Nursing \& Midwifery, Qazvin University of Medical Sciences, Qazvin , Iran

Type of article: Original

\begin{abstract}
Background: Regular physical activity has been considered as health promotion, and identifying different effective psycho-social variables on physical has proven to be essential.

Objective: To identify the relationship between decisional balance and self-efficacy in physical activities using the transtheoretical model in the members of a retirement center in Rasht, Guillen.

Methods: A descriptive cross-sectional study was conducted in 2013 by using convenient sampling on 262 elderly people who are the members of retirement centers in Rasht. Data were collected using Stages of change, Decisional balance, Self-efficacy and Physical Activity Scale for the Elderly (PASE). Data was analyzed using SPSS-16 software, descriptive and analytic statistic (Pearson correlation, Spearman, ANOVA, HSD Tukey, linear and ordinal regression).

Results: The majority of participants were in maintenance stage. Mean and standard deviation physical activity for the elderly was $119.35 \pm 51.50$. Stages of change and physical activities were significantly associated with decisional balance and self-efficacy $(\mathrm{p}<0.0001)$; however, cons had a significant and reverse association. According to linear and ordinal regression the only predicator variable of physical activity behavior was selfefficacy.

Conclusion: By increase in pros and self-efficacy on doing physical activity, it can be benefited in designing appropriate intervention programs.

Keywords: Physical Activity, Aged, Transtheoretical Model
\end{abstract}

\section{Introduction}

The worlds elderly population is expected to double by the year 2040 (1), In 2006, the United Nations estimated the total number of 687 million, 923 thousand elderly people of the world, and this number will reach 968 million, 153 thousand by 2050 (2). At present, the elderly population are 5.5 million in Iran and we expect 25-30 percent of the population will be over 50 years old in 2031 (3). Male and female life expectancy was computed to be 72.2 and 73.9 years respectively (4). Results show that 8.77 percent of Guillen's population are elderly people, hence Guillen is the oldest province (5). About two-thirds of elderly people suffer from chronic illness and reduction in ability and

\section{Corresponding author:}

Leila Dehghankar, Qazvin University of Medical Sciences, Qazvin, Iran

Tel: +98.9366206798, Fax: +98.2833338034, Email: Dehghan247@gmail.com

Received: November 27, 2016, Accepted: March 04, 2017, Published: May 2017

iThenticate screening: February 08, 2017, English editing: May 01, 2017, Quality control: May 12, 2017

(C) 2017 The Authors. This is an open access article under the terms of the Creative Commons Attribution-NonCommercialNoDerivs License, which permits use and distribution in any medium, provided the original work is properly cited, the use is non-commercial and no modifications or adaptations are made. 
operations in addition to changes due to age in structure and physical ability (6). Nowadays, lifestyle changes and physical activity reduction are considered as risk factors of cardiovascular diseases, diabetes mellitus, hypertension, osteoporosis, mental disorders, obesity and malignant diseases (7). Regular physical activity can be considered as one of the most important items of lifestyle, particularly in the elderly (8), lack of physical activity is considered as a risk factor in health (9) and forth risk factor global mortality (10), thus, increasing the level of physical activity is considered as a critical affair for public health (9). Regular physical activity helps to protect and improve physical and mental health in individuals (11) and promotion of mental health also reduces symptoms of depression and anxiety, enhances life satisfaction and promotes life quality (2). Participating in a physical activity is also an important part of lifestyle particularly for the elderly (12). To achieve the benefits of physical activity, it is essential that people do regular activities at the appropriate level (10). According to the presented statistics by the World Health Organization (WHO), the burden of disease due to inactivity was estimated at 1240000 deaths and 1243000 adjusted life years in the year 2000 in the Eastern Mediterranean region (13). Sixty percent of adults in the United States do not participate in regular sport programs and 31 percent of these people never do exercise, while $66 \%$ of Iranian elderly people who are over 75 years old do not participate in any regular physical activity (14). As the 2010 study of Salehi et al. shows, 30.25\% of elderly people participated in some kind of regular physical activity in Tehran (15). Given the importance of healthy behavior, various models were developed describing why and how people change their lifestyle (7) that these models, as for strategy and goals, help to check interventions, guesses and assumptions and so today, using models is almost necessary for educational and health promotion experts (16). The transtheoretical model is a most comprehensive and integrated model of behavioral changes among health behavioral models, this model has been widely applied in studies to enhance health issues in behavioral changes and interventions in physical activities (17). The model has been derived from the basic models of psychotherapy as a behavioral change model. Stage of change is one of the aspects of the model that shows the preparation stage of a person for behavioral change (18). This model is a development process by a series of stages, regarding behavioral changes (7) that includes: pre-contemplation stage, contemplation, preparation, action and maintenance. In the precontemplation stage, the person will not have thought about behavioral change for at least 6 months. In the contemplation stage, the person is preparing to make a change soon, usually within the next month. The action stage is a stage at which the person has created an appropriate change in his/her lifestyle during the last 6 months. In the maintenance stage, we see a longer establishment and strengthening period of behavioral change -more than 6 months- but active and conscious efforts are needed to maintain it (19). The process is not like a five stage change in a straight line, as it is possible that a person in the primary change stage returns several times so that the maintenance stage can be attained (7). Decisional balance is the other structure of stages of change. According to this model, behavioral change occurs when behavioral change adherents are more important than opposition. Then educators must try to increase adherence in addition to decreasing opposition (20). People consider the costs compared to the advantages when deciding whether or not to change. This item is considered as a decisional balance in behavioral change. This is when people cognitively evaluate the good aspects and the not so good aspects (the pros and cons) of behavior and they also evaluate the reason for changing or not changing (21). According to decisional balance for a successful behavioral change such as exercise, a person must know the pros of behavioral change more than its cons. Pros of exercise appear to be more than cons and its costs for people who are at the maintenance stage as a result, they are encouraged to continue to exercise. Generally, positive views and belief's increase while moving from the early stages of exercise to the last, and conversely, negative views and beliefs decrease (21). The other structure is self-efficacy, which is the confidence in ability that a person has, to successfully perform a specific task (7). According to this structure, in order to maintain behavioral change, people who are in the process of change need to have a high level of self-efficacy and assurance when they are dealing with particular situations in which there is a possibility of doing unhealthy behavior (21). The study of Lee et al. showed that most of the elderly who were in the contemplation stage of exercise, behavioral change stage and process of change, perceived that pros and self-efficacy had a significant difference during stage of change, and perceived that the cons did not have significant difference (22). The study of Kang and et al. showed that there is a significant difference between physical activity with self-efficacy, perceived pros, and cons and also self-efficacy and perceived pros showed significant difference during stage of change (23). The study of Mori et al. showed that adult men significantly have a higher self-efficacy score in contemplation stage than pre-contemplation stage. Adult women significantly have a higher self-efficacy score in maintenance stage than action stage and in contemplation stage than pre-contemplation stage (24). Another study showed that the elderly were mostly in pre-contemplation stage and preparation stage, and people who had more self-efficacy barriers mostly were in contemplation stage than maintenance stage. In this study, exercise attitude, perceived behavioral controlling and self-efficacy barriers were obtained as independent predictor (25). The study of Salehi et al. showed that perceived pros and perceived cons can predict the physical activity stage of change (16). Although different studies have been conducted about stage of 
change and its relationship with physical activity in Iran and other countries, as respects to cultural differences, geographical conditions have must effort on creation and maintenance of physical activity behavior, in performing a study aimed to assess the level of physical activity and the relationship between decisional balance and physical activity's self-efficacy based on the transtheoretical model in the elderly in Guillen city.

\section{Material and Methods}

The present study was conducted using a descriptive-cross-sectional design from February to April, 2013 on 262 subjects from the members of retirement centers in Rasht. The study population included all retired elderly people (sixty years or over) who referred to the active retired center in Rasht city, of which there are around 10,800 state retired elderly. According to proportion of each center with total sample size, the number of members of each center were calculated then sampling was performed. Sample size in 4 centers was less than 10 because of low membership, then in order to assimilate, we increased it to 15, finally a sample size of 262 elderlies was obtained. Inclusion criteria for study was being sixty or over, having membership of active retired center of Rasht, having ability to communicate verbally when responding to questions, ability to carry out daily activity without any help or instrument, not having debilitating disease, disability, surgery, giving consent to participate in the study, being retired for more than 6 months, were chosen. In order to gather data, the researchers referred to active retired centers of Rasht (research environments). After passing ethical and legal levels, obtaining licenses and approval from the Deputy for Research and Technology and presenting approval and explaining goals of research to authorities, face to face interviews were conducted while assuring the subjects that all personal information would be private, and anonymous. After obtaining consent from subjects qualified for study, the questionnaire was completed by researchers. To gather data, a standard questionnaire was used. The first part concerned demographic data, the second part was related to assessing the stage of exercise change, developed by a five-item questionnaire of stage of exercise change by Marcus et al. (26). The second section consists of a questionnaire on decisional balance structure developed by Nigg. et al. (27) which consists of ten questions with two scales, pros and cons, it was measured according to a Likert scale which was based on a 5 - 25 score. Physical activity's self-efficacy structure was assessed using a questionnaire developed by Marcus et al. (20), which consisted of six questions, each one has five choices and the range of score is 6 - 30. The third part of the questionnaire assesses physical activity levels by Physical Activity Scale for the Elderly (PASE scale) $(28,29)$. This scale evaluates some information about time spent by subjects for walking, average and intense activity and household and work-related activities during the past 7 days. Total PASE scores were calculated by multiplying the amount of time spent in each activity (h/d) or participation in activities (yes/no) in the respective weight of each activity and finally adding up all multiplication results in order to obtain the PASE total score. In a study conducted by Washburn et al. (28), the PASE scores were reported to have a range from 0 to 400 or higher (30). These questionnaires have also been used in studies conducted in Iran (3, 15), also in this study, to determine the validity of the content of the 13 nursing and health professionals, content validity index (CVI) was calculated. To determine the validity and reliability of the questionnaire, Cronbach's alpha and test-retest methods were used, so that in a pilot study, a questionnaire within two weeks was twice in the hands of a group of fifteen people from the targeted population. Retest coefficients stage of change structure was 0.92 , Cronbach's Alpha coefficients self-efficacy structure 0.71 and decisional balance 0.70. Finally, gathered data was analyzed using SPSS-16 software, descriptive and analytic statistic (Pearson correlation, Spearman, ANOVA, HSD Tukey, linear and ordinal regression).

\section{Results}

Results showed that the mean age of the participants was 64.95 \pm 5.03 and in age ranged 60-64 years. The demographic characteristics have been displayed in Table 1. Results showed that mean and Standard deviation of PASE was 119.35 \pm 51.50 . The level of PASE in the domain of leisure activities showed the highest mean score PASE in walking activity and lowest mean in intense physical activity and in the domain of household activity, the highest mean in the household light activity and lowest mean in gardening activities outside the home. The maximum mean in household light activity and a minimum of physical activity was very intense. Among the demographical variables, only the relationship between age and the amount of physical activity was found to be significant $(\mathrm{p}=0.04)$ so that with increasing age, physical activity decreased. Results showed that the percentage of the participants who were at the stages of pre-contemplation, contemplation, preparation, action, and maintenance were $21.8 \%, 16.4 \%, 22.5 \%, 5 \%$, and $34.4 \%$, respectively. Results showed that the scores of self-efficacy, pros and cons were significantly different at the different stages of exercise behavioral change (Table 2). Results according to Pearson and Spearman correlation showed there was significant association between pros and self-efficacy with physical activity, however, cons had a significant and reverse association $(\mathrm{p}<0.0001)$; According to linear and ordinal regression, the only predicator variable of physical activity behavior was self-efficacy. 
http://www.ephysician.ir

Table 1. Sample demographics characteristics

\begin{tabular}{|l|l|l|}
\hline Characteristics & Categories & Frequency (\%) \\
\hline Gender & Male & $141(53.8)$ \\
\cline { 2 - 3 } & Female & $121(46.2)$ \\
\hline \multirow{4}{*}{ Education } & Illiterate & $3(1.1)$ \\
\cline { 2 - 3 } & Middle school & $36(13.7)$ \\
\cline { 2 - 3 } & High school & $186(71)$ \\
\cline { 2 - 3 } & College and above & $37(14.1)$ \\
\hline \multirow{5}{*}{ Marital status } & Married & $219(83.6)$ \\
\cline { 2 - 3 } & Not married & $2(0.8)$ \\
\cline { 2 - 3 } & Widowed & $40(15.3)$ \\
\cline { 2 - 3 } & Divorced & $1(0.4)$ \\
\hline \multirow{5}{*}{ House } & Own & $229(87.4)$ \\
\cline { 2 - 3 } & Rental & $33(12.6)$ \\
\hline \multirow{5}{*}{ BMI } & $<18.5$ & $4(1.5)$ \\
\cline { 2 - 3 } & $18.5-24.9$ & $118(45)$ \\
\cline { 2 - 3 } & $25-29.9$ & $100(38.2)$ \\
\cline { 2 - 3 } & $>30$ & $40(15.3)$ \\
\hline
\end{tabular}

Table 2. The mean and standard deviations for self-efficacy, perceived benefits, and barriers to physical activity behavior separate stage of change

\begin{tabular}{|l|l|l|}
\hline Structures of Stages of Change & p-value (ANOVA) & HSD Tukey \\
\cline { 2 - 3 } & $<0.0001$ & $\mathrm{PC}<\mathrm{C}<\mathrm{PR}, \mathrm{A}, \mathrm{MT}$ \\
\hline Self-Efficacy & $<0.0001$ & $\mathrm{PC}<\mathrm{C}, \mathrm{PR}<\mathrm{MT}$ \\
\hline Perceived benefits & $<0.0001$ & $\mathrm{PC}, \mathrm{C}<\mathrm{MT}$ \\
\hline Perceived barriers & $<0.0001$ & $\mathrm{PC}, \mathrm{C}$.PR $<$ MT \\
\hline
\end{tabular}

\section{Discussion}

This study aimed to assess the level of physical activity and the relationship between decisional balance and physical activity's self-efficacy based on the transtheoretical model in the elderly in Guillen city. Results showed that mean of PASE was 119.35, and subjects' score of physical activity was less than $30 \%$ of PASE score that the mean was higher than the Norliana et al. (31), Hagiwara (32), and Ngai (33) studies but in the Salehi study on the elderly in Tehran (15), physical activity mean was 124.79. A different study population and culture of population can be considered the conflict reason, because physical activity is influenced by several items such as physical and mental aspects and individual perception of doing it. In this study, the highest mean score PASE was in walking activity and lowest mean in intense physical activity and in the domain of household activity, the highest mean was in the household light activity and lowest mean in gardening activities of outside the home, which was in accordance with some other studies $(28,32,34)$. Only in the household activity and highest PASE score was there conflict with the Hagiwara study, so that in the Hagiwara study, the highest PASE score was in the household activity domain, yard care, home repair and the lowest PASE score was in yard care. Results showed that the amount of physical activity in the elderly in Guillen according to PASE was light exercise, but its continuity was much. Maybe the result is in that these elderlies were living in apartments and additionally, due to the economic issues they could not use appropriate sports equipment. It is possible, they were limited to just walking regularly, conversely after retirement, they tend to do sitting activities out of house. These factors cause the amount of physical activities to become light. PASE evaluates leisure time activities, household and work-related activities, and because of different lifestyles in various societies, we have different results. The results showed that there was a significant relationship between ageing and physical activity decrease, the findings were in accordance with Salehi (15) and Dumith (36), and also in the Norliana et al. (31) and Murtagh et al. (35) studies. By aging, the amount of physical activity decreases, it is logical that by aging, the elderly have less regard for physical activity because of physiological and mental changes. The study showed that most of the subjects were at maintenance stage and that finding was in accordance with the Kang et al. and (23) Kloek et al. studies (34), but it was in contrast with the Salehi and (15), Dumith (36), Mazloomy et al. studies (37), in both studies, most of the subjects were in pre-contemplation and contemplation stage. The reason that this study has resulted in this specific finding derives from the fact that physical activity has been considered as a social-context-based behavior. Therefore, it varies from one society to another. Accordingly, individuals are expected to be in the different stages of behavioral change in different societies so that in our study 
about the Guilanian elderly, most of the subjects were at the final stage of behavioral change. In contrast, some problems such as heavy traffic, too many apartments and not enough space for exercise cause the elderly in Tehran to locate in the primary stages of behavioral change. Results showed that self-efficacy has significantly increased at maintenance stage than pre-contemplation. Also, results showed that physical activity self-efficacy leads people to move from an inactive lifestyle to active. It is expected that people with higher self-efficacy have a more physical activity than people with lower self-efficacy and also, during the behavioral change stage, people who have higher self-efficacy move to the higher behavioral change stage, which is according to the findings of other researchers (15, $22-24,38)$. Results showed that perceived pros have significantly increased at maintenance stage than precontemplation and perceived cons have significantly increased at pre-contemplation stage than maintenance which is in accordance to the findings of other researchers $(15,22-24,38)$. The researcher mentions geographical conditions and different cultures as the reason of this conflict, also in Kang's study, people over 65 years entered to study and maybe 60-65-year-old recognized perceived cons because they were younger than our study participants. By increasing the perceived pros, individuals' physical activity behavior moved toward higher levels, because the person who has more perception of exercise benefits would have found its importance and continued this exercise behavior, when barriers of doing physical activity are reduced, subjects can move from lower stages of behavioral change to higher stages. Results showed significant association between self-efficacy and physical activity and the findings were in accordance with those of Kang and et al. (23), but were against those of Salehi et al. (15). It is logical that by increasing self-efficacy, the amount of physical activity increases, because self-efficacy is a confidence of ability which people have in encountering dangerous situations, and if they have more self-efficacy and resist more against temptation, they will improve in doing physical activity and its continuity. The PASE scale encompasses a wide ranged evaluation of physical activity of people such as housekeeping tasks or shopping and exercise, and because PASE has been considered as a social-context-based behavior, it will vary from one society to another. Results showed that there were significant associations between perceived cons and physical activity and the finding was in accordance with that of Kang et al. (23), but was against that of Salehi and et al. (15). Salehi, in his research, found that there was no significant association between perceived pros and perceived cons with physical activity levels, and by reducing the perceived cons of physical activity behavior, the level of physical activity will increase if every person realizes that by breaking the barriers of doing physical activity, they can have more physical activity and continue this behavior. If during the time, a person perceives more benefits of physical activity behavior, the amount of physical activity will increase, but in this study, there was no significant association between perceived pros with physical activity, probably because of this reason that most of the subjects were at the maintenance stage of behavior change and had continuity in the exercise, there were no perceived pros. Results showed that the only predicator variable of physical activity behavior was self-efficacy, so that the elderly with more self-efficacy had more participation in physical activity than the elderly with less self-efficacy, and also, the Kang (23) and Kim (38) study showed that the strongest predictor variable was self-efficacy for elderly physical activity behavior. In the Salehi (15) and Kosma (39) studies, the self-efficacy variable and perceived pros of physical activity variable were predictors of physical activity behavior. Ghahremani et al. (40) showed that the only predictor of physical activity is self-efficacy.

\section{Conclusions}

Results showed that there was a significant association among stages of change and physical activities with decisional balance and self-efficacy and predicator variable of physical activity behavior was self-efficacy. This study emphasizes on the importance of related factors to physical activity for health care researchers, especially health promoters for performing effective programs on physical activity who need to recognize self-efficacy and perceived pros and cons. It is suggested that a complementary study on the elderly be done about the impact of stages of behavioral change on physical activity throughout Rasht and the other retirement centers which can be a good path for future researches on this topic.

\section{Acknowledgments:}

The authors would like to express their gratitude to the Deputy of Research Guillen University of Medical Sciences, by accepting the financial support for a graduate student's thesis, registration number 90212, and also sincerely appreciate the master of state retired and masters of state retired center in Rasht.

\section{Conflict of Interest:}

There is no conflict of interest to be declared.

\section{Authors' contributions:}

All authors contributed to this project and article equally. All authors read and approved the final manuscript. 


\section{References:}

1) Smagula SF, Stone KL, Fabio A, Cauley Jane A. Risk factors for sleep disturbances in older adults: Evidence from prospective studies. Sleep Med Rev. 2016; 25: 21-30. doi: 10.1016/j.smrv.2015.01.003. PMID: 26140867, PMCID: PMC4506260.

2) Aghamollaie T, Tavafian S, Hasani L. Self-efficacy, perceived benefits, perceived barriers to regular physical activity among students in Hormozgan University of Medical Sciences. Iranian Journal of Epidemiology. 2008; 4(3-4): 9-15 [in Persian].

3) Ebrahimi Fakhar MR, Zand S. Nutritional status and associated factors in elderly residents in nursing homes. Journal of the Iranian Institute for Health Sciences Research. 2012; 12 (2): $143-9$ [in Persian].

4) Ghafarian shirazi H, Mahmoudi M, Mohamad K, Rahimi Froshani A, Jafari N, Ostovar R, et al. Life expectancy at birth for the rural population of Islamic Republic of Iran, by sex and age groups 2007. Life Science Journal. 2012; 9(3): 180-3 [in Persian].

5) Kor A, Mosavi S, Reza Masoleh SH, Behnampor N. Assessment of the correlation between lifestyle and quality of sleep in elderly who referred to retirement center in Rasht. J Holist Nurs Midwifery. 2008; 17(2): 15-22 [in Persian].

6) Masoumi N, Jafroudi Sh, Ghanbari A, kazemnejad Leile E. Assessment of retired elderly's people autonomy and its affecting factors in Rasht. Journal of Guillen University of Medical Sciences. 2011; 21(65): 51-90 [in Persian].

7) Moattari M, Shafakhah M, Sabet Sarvestani R. Assessing Stages of Exercise Behavior Change, SelfEfficacy and Decisional Balance in Iranian Nursing and Midwifery Students. International Journal of Community based Nursing and Midwifery. 2013; 1(2): 121-9.

8) Bayati M. Physical Inactivity and Sedentary Lifestyle. Iranian Journal of Endocrinology and Metabolism. 2012; 13(5): $537-9$ [in Persian].

9) Sørensen M, Gill DL. Perceived barriers to physical activity across Norwegian adult age groups, gender and stages of change. Scand J Med Sci Sports. 2008; 18(5): 651-63. PMID: 18086263. doi: 10.1111/j.16000838.2007.00686.x.

10) Parhoodeh Y, Khezeli M, Bakhtiyari M, Delpisheh A, Latifi A. Effects of Education Based on Trans theoretical Model on Physical Activity of College Students. Journal of Health System Research. 2012; 8(2): $320-9$.

11) Moschny A, Platen P, Klaassen-Mielke R, Trampisch U, Hinrichs T. Barriers to physical activity in older adults in Germany: a cross-sectional study. Int J Behav Nutr Phys Act. 2011; 8: 121. doi: 10.1186/14795868-8-121. PMID: 22047024, PMCID: PMC3225299.

12) Azizan A, Justine M, Siew Kuan Ch. Effects of a Behavioral Program on exercise Adherence and exercise Self-Efficacy in Community-Dwelling Older Persons. Current Gerontology and Geriatrics Research. 2013: 1-10. doi: 10.1155/2013/282315.

13) Sharifirad GR, Mohebi S, Matlabim M. The relationship physical activity in middle age and cardiovascular problems in old age in retired people in Isfahan. Ofogh-e-Danesh. 2007; 13 (2): 57-64 [in Persian].

14) Nejati V, Kordi R, Shojaee F. Evaluation of Effective Motivators and Barriers of Physical Activity in the Elderly. Iranian Journal of Aging. 2009; 4(14): 52-8 [in Persian].

15) Salehi L, Eftekhar H, Mohammad K, Taghdisi MH, Shojaeizadeh D. Physical Activity among a Sample of Iranians Aged Over 60 Years: An Application of the Trans theoretical Model. Arch Iran Med. 2010; 13(6): 528-36. PMID: 21039010.

16) Khezli M, Ramezankhani A, Bakhtyari M. The impact of education on nutritional knowledge and stages of change fruit and vegetable intake in the elderly: Based on stages of change model. Journal of Mazandaran University of Medical Sciences. 2012; 22(9): 90-100.

17) Spencer L, Adams TB, Malon S, Roy L, Yost E. Applying the Trans theoretical model to exercise: a systematic and comprehensive review of the literature. Health Promote Pract. 2006; 7(4): 428-43. doi: 10.1177/1524839905278900. PMID: 16840769.

18) Moeini B, Rahimi M, Hazaveie SM, Allahverdipoor H, Moghimbeygi A, Mohammadfam I. Effect of education based on Trans-theoretical model on promoting physical activity and increasing physical work capacity. Journal of Military medicine. 2010; 12(3): 123-30.

19) Farmanbar R, Dehghankar L, Mirhadian L, Kazemnejad Leili E, Emami Sigarodi A. Physical Activity's Related Factors Based on Trans theoretical Model in Older Adults Guillen In 2013. J Appl Environ Biol Sci. 2014; 4(2): 24-30.

20) Saffari M, Shojaeizadeh D, Ghofranipour F, Heydarnia A, Pakpuro AH. Health education and promotion, Theories, models and methods. 2th ed. Tehran: Sobhan; 2012 [in Persian]. 
21) Charkazi A, Khoshnevisam M, Mafakheri Z. Transtheoretical Model and its Application in Exercise. Gorgan: publisher faraghi makhtomaghli; 2011.

22) Lee Y, Park N, Kim Y. Process of Change, Decisional Balance, Self-efficacy and Depression across the Stages of Change for Exercise among Middle Aged Women in Korea. Taehan Kanho Hakhoe Chi. 2006; 36(4): 587-95. doi: 10.4040/jkan.2006.36.4.587. PMID: 16825842.

23) Kang SJ, Kim SC, Kim YH. Korean Older Adult's Physical Activity and Its Related Psychosocial Varieables. Journal of Sports Science and Health. 2012; 13 (3): 89-99.

24) Moria K, Suzukib H, Wanga DH, Takakia J, Takigawaa T, Oginoa K. Relationship of Psychological Factors with Physical Activity Stage of Change in Prime-and Middle-aged Japanese. Acta Media Okayama. 2009; 63(2): 97-104. PMID: 19404341.

25) Thøgersen-Ntoumani C. An ecological model of predictors of stages of change for physical activity in Greek older adults. Scand J Med Sci Sports. 2009; 19: 286-96. doi: 10.1111/j.1600-0838.2007.00751.x. PMID: 18282227.

26) Marcus BH, Selby VC, Niaura RS, Rossi JS. Self-efficacy and the stages of exercise behavior change. Research Quarterly for Exercise and Sport. 1992; 63: 60-6. PMID: 1574662. doi: 10.1080/02701367.1992.10607557.

27) Nigg CR, Rossi JS, Norman GJ, Benisovich SV. Structure of decisional balance for exercise adoption. Annals of Behavioral Medicine. 1998; 20: S211. 1998.

28) Washburn RA, Smith KW, Jette AM, Janney CA. The Physical Activity Scale for the Elderly (PASE): Development and evaluation. J Clin Epidemiol. 1993; 46(2): 153-62. PMID: 8437031.

29) Physical activity scale for the Elderly and Paffenbarger Physical Activity Index. New England Research Institute. The center for STRONG Medicine. 1-4.

30) Martin KA, Rejeski WJ, Miller ME, James MK, Ettinger WH Jr, Messier SP. Validation of the PASE in older adults with knee pain and physical disability. Med Sci Sports Exerc. 1999; 31(5): 627-33.

31) Ismail N, Hairi F, Choo WY, Hairi NN, Peramalah D, Bulgiba A. The Physical Activity Scale for the Elderly (PASE): Validity and Reliability Among Community- Dwelling Older Adults in Malaysia. Asia Pac J Public Health. 2015; 27(8 Suppl): 62S-72S. doi: 0.1177/1010539515590179. PMID: 26058900.

32) Hagiwara A, Ito N, Sawai K, Kazuma K. Validity and reliability of the Physical Activity Scale for the Elderly (PASE) in Japanese elderly people. Geriatr Gerontol Int. 2008; 8(3): 143-51. PMID: 18821997. doi: 10.1111/j.1447-0594.2008.00463.x.

33) Ngai SP, Cheung RT, Lam PL, Chiu JK, Fung EY. Validation and reliability of the Physical Activity Scale for the Elderly in Chinese population. J Rehabil Med. 2012; 44(5): 462-5. PMID: 22549657. doi: 10.2340/16501977-0953.

34) Kloek GC, van Lenthe FJ, van Nierop PW, Schrijvers CT, Mackenbach JP. Stage of change for moderateintensity physical activity in deprived neighborhoods. Prev Med. 2006; 43(4): 325-31. doi: 10.1016/j.ypmed.2006.05.003. PMID: 16808969.

35) Murtagh EM, Murphy MH, Murphy NM, Woods C, Nevill AM, Lane A. Prevalence and correlates of physical inactivity in community-dwelling older adults in Ireland. PLoS One. 2015; 10(2): e0118293. doi: 10.1371/journal.pone.0118293. PMID: 25671621, PMCID: PMC4324635.

36) Dumith SC, Gigante DP, Domingues MR. Stages of change for physical activity in adults from Southern Brazil: a population-based survey. Int J Behav Nutr Phys Act. 2007; 4(25): 1-10. doi: 10.1186/1479-58684-25. PMID: 17555603, PMCID: PMC1904456.

37) Mazloomy S, Mohammadi M, Morovati Sharifabad MA, Falahzade H. A Study of the Decisional Balance's Role in Exercise Status among Yazd's Staff on the Basis Process of Change Model. Tabib shargh. 2009; 11(2): 57-65 [in Persian].

38) Kim YH, Cardinal BJ, Lee JY. Understanding exercise behavior among Korean adults: a test of the Trans theoretical model. Int J Behav Med. 2006; 13(4): 295-303. doi: 10.1207/s15327558ijbm1304_4. PMID: 17228987.

39) Kosma M, Cardinal BJ, McCubbin JA. Predictors of physical activity stage of change among adults with physical disabilities. Am J Health Promot. 2004; 19: 114-7. PMID: 15559711.

40) Ghahremani L, Niknami Sh, Mosavi MT, Heidarnia AR, Karimzadeh Shirazi K, Babaei GH. Trans theoretical Model-based (TTM) Interventions to Improve Physical Activities in Elderly Men. Journal of Armaghan danesh. 2008; 13(1): 77-88 [in Persian]. 